\title{
Panorama do mérito jornalístico: prêmios em jornalismo e sua estruturação
}

\author{
Robson Borges Dias
}

\section{Introdução}

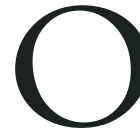

s prêmios em jornalismo são dispositivos comuns à cultura profissional jornalística. No Brasil, na área de comunicação, foi tema de uma dissertação com Cassol (1997), ao tratar das mudanças na reportagem do noticiário gaúcho que seriam influência do Prêmio Esso. Foi o único trabalho do tipo nos anos 1990.

Nos anos 2000, houve um crescimento no interesse sobre esse tema com cinco pesquisas: Santos (2004) tratou da pauta dos direitos humanos a partir de vencedores do Prêmio Vladimir Herzog. Magno (2006) recuperou a questão dos gêneros jornalísticos em reportagens premiadas pelo Prêmio Esso. Passos (2007) utilizou uma abordagem semiótica sobre sentidos de fotografias premiadas, também no âmbito do Prêmio Esso. E Mora (2008) concentrou-se sobre o Concurso Tim Lopes (premiação da Agência de Notícias dos Direitos da Infância - ANDI; que não se confunde com o Prêmio Tim Lopes, da Rede Globo) sobre sugestões de pautas sobre infância e adolescência, que concorriam a um financiamento de uma Ong especializada: a ANDI. Na sequência, Dias (2008) também utilizou a plataforma de atuação da ANDI para investigar a influência do Prêmio Jornalista Amigo da Criança sobre o profissional de jornalismo.

$\mathrm{Na}$ década vigente, anos 2010, Gonçalves (2010) ao pesquisar repórteres que trabalham no Legislativo, no que se convencionou chamar de Mídia das fontes (Sant'Anna, 2009; Borges, 2008), listou vários prêmios que jornalistas servidores ganhavam atuando em mídia corporativa. Até então, todos os estudos foram dissertações. A primeira tese apresentada sobre o tema foi a de Castilho (2010), sobre 
a identidade profissional e as relações entre imprensa e Estado, durante o período militar (1964-1978). E Dias (2013), estudo que dá base a este artigo, que estudou 114 premiações em jornalismo e produziu um mapa da atuação de diversos prêmios. Recentemente, Ferreira e Faccin (2013) publicaram na revista BJR um estudo sobre o Prêmio Imprensa Embratel. E outro trabalho sobre outros dois prêmios: Prêmio Esso de Jornalismo e o Prêmio Imprensa Embratel/Claro (Ferreira, 2014). Atualmente, existem iniciativas não-científicas que trabalham com prêmios e sua sistematização, como o Ranking JornalistasECia, do Centro de Memória dos Prêmios de Jornalismo do Brasil, inaugurado em 2011, que trabalha com ranqueamento dos jornalistas mais premiados do ano, além de memória, registro e arquivo dos prêmios brasileiros.

Em relação aos estudos científicos, a maioria foca como objeto os vencedores das premiações, ou seja, as matérias, profissionais e empresas que mais se aproximam do ethos prescrito pelos prêmios. E as discussões circundam as questões sobre gêneros jornalísticos, narrativas, produção de sentido e identidade profissional (Dias, 2014e). Na abordagem do presente artigo, partimos não apenas da perspectiva dos vencedores, mas dos prêmios em si: tomando-os como objeto. O olhar não é sobre quem é premiado, mas sobre quem os premiadores querem certificar o mérito jornalístico. Tanto que a base metodológica desta pesquisa utiliza análise de conteúdo dos editais e regulamentos de 114 premiações, a partir de tratamento qualitativo e quantitativo. A amostra é feita de regulamentos de premiações (1), editados no ano de 2010 ou 2011 (2), em língua portuguesa (3), que certificavam profissionais da mídia brasileira com trabalhos e atuação em território nacional (4).

Apresentamos nas seções seguintes 14 condições sobre as quais os prêmios se estruturam: se as assessorias terceirizam (ou não) (1), aspectos quanto à soberania do júri (2), quanto à composição do júri (3), sobre controle externo via auditoria (4), sobre controle interno via instância recursal (5), quem são os jornalistas premiados: profissionais ou estudantes (6), quem são os sindicatos e associações profissionais e patronais que apoiam as premiações (7), temas humanísticos mais utilizados (8), temas globais mais utilizados como as 8 Metas do Milênio (9), qual tipo de mídia é mais utilizado (10), quais os modelos jornalísticos mais utilizados (11), a questão do direito autoral e patrimonial dos trabalhos (12), a apropriação de material para fins didáticos (13) e quais trabalham com responsabilidade legal relativa à questão do plágio (14).

Perceba que as 14 condições estruturantes são pela ótica das organizações que premiam. E o que elas consideram em seus editais e regulamentos como práticas correntes nesse cenário de certificação do mérito. E, por se tratar de um formato artigo (40.000 caracteres), logicamente a análise é descritiva da realidade encontrada no enfrentamento da pesquisa empírica, se reportando quando necessário a questões acessórias, discussões e resultados já desenvolvidos em outras oportunidades e formatos científicos (indicados ao longo do texto). 


\section{Estruturante I - As assessorias terceirizam (ou não) os prêmios?}

Existe uma ideia de que os próprios repórteres se premiam, entre pares, por comporem os juris. Entretanto, desde o Prêmio Esso, em 1955, as organizações e os assessores é que ajudaram a definir o padrão de Jornalismo Informativo e Jornalismo Investigativo, no Brasil (Dias, 2013: 33). Na pesquisa foi identificado que a grande maioria das premiações não toca neste assunto de modo expresso: se terceiriza (ou não) seu trabalho. Apenas 5\% revelam algum tipo de transferência de execução e gestão do prêmio a empresas terceirizadas. Este item verificava a autonomia dos assessores nos processos de certificação do mérito dos repórteres, o que poderia configurar um trabalho de jornalistas para jornalistas, aos pares. Além de não haver menção a essa condição nos editais/regulamentos, os prêmios não eram claros sobre isso. A classificação número (3) tenta checar isso: sobre a composição do júri.

Nos estudos de Agendamento e Newsmaking se fala muito de definidores primários (Hall et al., 1993) em relação às rotinas produtivas (Tuchman, 1993), mas não se comenta muito sobre as rotinas cognitivas (Sousa, 2003) ou limites cognitivos (Traquina, 1993) relativos à subjetividade de cada jornalista. Este item tentou checar se os prêmios trabalham com jornalistas (assessores) acessando a cultura profissional de jornalistas (repórteres) a partir dos processos organizacionais dos prêmios. Tal fato valida não apenas o doutrinamento da pauta das redações (rotinas produtivas), mas também a cosmovisão dos jornalistas (rotinas cognitivas) (Dias, 2014a).

\section{Estruturante 2 - Aspectos quanto à soberania do júri nos prêmios}

Quanto à soberania do júri, alguns prêmios dão soberania plena (74\%), relativa $(7 \%)$ às comissões que avaliam. A relativização da soberania está em relação à auditoria e não às instâncias recursais (ao contraditório). O contraditório ou recursos agem como queixa pedindo anulação ou diminuição dos poderes conferidos aos avaliadores (como: desempate, desclassificação e autoridade). Nem todos expressam os poderes e como são aplicados (19\%). Os 7\% de soberania relativa dizem respeito a prêmios auditados que podem ser questionados em seus processos pelo auditor externo. É um tipo de controle. Mas, ressalta-se que o auditor não recebe reclamações dos candidatos. Ele age acompanhando a lisura dos processos a partir de seu olhar.

Sobre o "profissionalismo" como "método de controle do trabalho" (Traquina, 2001: 107) dando o status de bom ou mau jornalismo, há o explícito reconhecimento do domínio das técnicas do fazer, além do saber, como procedimento jornalístico. Mas, tacitamente, também há a doutrinação da subjetividade dos jornalistas, no tocante à sua cosmovisão a partir da cultura meritocrática premiativa dentro da cultura profissional jornalística (Dias, 2014b). Nos editais/regulamentos, o tipo de controle mais comum é indireto, com a composição das bancas com

42 ALCEU - n.33 - jul./dez. 2016 
jornalistas de entidades representativas patronais e profissionais, o que assegura a avaliação par a par, mas não se institui como instância de controle, efetivamente: como auditorias. A soberania do júri é uma categoria que se relaciona à de instâncias recursais, a ser tratada mais à frente. "Casos omissos" é uma expressão chavão para a soberania do júri frequentemente expressada, assim como: "hipóteses não contidas neste regulamento".

\section{Estruturante 3 - Quanto à composição do júri nos prêmios}

Nem sempre o júri é composto com membros de notório saber na área. Muitos premiadores utilizam-se apenas dos integrantes de suas assessorias de comunicação, aliadas à diretoria da organização (26\%), avaliado pelo índice chamado Institucional (sem jornalistas). Entretanto, existem comissões que recebem a participação de sindicatos patronais, profissionais e de jornalistas de destaque no mercado (51\%), o que é a maioria. Também é perceptível como fator de estruturação e organização dos prêmios: certa tendência de se convocar acadêmicos para compor essas bancas.

Algumas comissões de júri são feitas apenas com a participação de patrocinadores, apoiadores e colaboradores. E há as que convocam representantes da sociedade que sequer têm conhecimento de práticas e técnicas do jornalismo (políticos, cantores, empresários famosos), gerando uma confusão entre convidados proeminentes nas cerimônias de entrega e nas composições de júri. Alguns omitem a forma com a qual é feita a composição do júri. Para efeito da pesquisa e, como problema na apuração, por não ter informação clara sobre o assunto não sabíamos, por exemplo, se o processo de avaliação do júri é feito com reuniões ou com a distribuição de fardos em que cada membro elege um vencedor.

A curiosidade aqui fica por conta do Prêmio Esso, na categoria de fotografia, em Fotojornalismo, e não fotografia artística, na qual o júri elenca um rol de premiáveis e os concorrentes votam pela internet na escolha de um vencedor. E o Prêmio Aberje tem audiência pública para apresentação oral dos trabalhos (como uma defesa), que é um momento no qual os concorrentes podem acompanhar os júris.

\section{Estruturante 4 - Sobre controle externo do prêmio via auditoria}

Quanto à Auditoria, a maioria não toca no assunto (98\%) de maneira expressa. Pode-se pensar, em termos de controle, que os auditados tenham instâncias recursais. Essa associação não é possível na amostra, pois nem todos os auditados (Prêmio Aberje, Prêmio Sebrae e Prêmio Comunique-se) tem instâncias recursais.

Há um mistério nos editais sobre o que é "auditoria independente" e "auditado internamente". O Prêmio Sebrae é o único que fala em ata da comissão. Contudo, não 
trata de como essa ata é disponibilizada para consulta. O Prêmio Automação de Jornalismo tem um júri que trabalha com uma plenária presencial. Remete a uma audiência pública, defesa perante banca, sabatina. O Prêmio Aberje tem audiência pública (sic) para apresentação oral dos trabalhos e também conta com um ombudsman.

Conceitualmente, lembremos que, em se tratando de prêmios, os padrões de conduta e normas de comportamentos são relativos à atuação indireta dos definidores primários frente a dissonâncias cognitivamente induzidas nos jornalistas em suas redações e rotinas produtivas (Dias, 2014a). Dentro do cotidiano de produção da notícia de cada profissional, existem as rotinas cognitivas: percepções que o jornalista tem da realidade, podendo, posteriormente, favorecer a avaliação do que é noticioso, além do fato das rotinas produtivas estarem confinadas nos limites cognitivos da racionalidade (Traquina, 1993: 93). Nesse aspecto, entendemos que até pode haver auditoria de processos, mas quem auditoria a cultura (profissional)? Esse item levanta essa discussão de como os jornalistas poderiam se resguardar (ou não) em fator em sistema perito ou sistema de avaliação pelos pares, uma discussão que segue para a sociologia das profissões (Dias, 2012c).

\section{Estruturante 5 - Sobre controle interno do prêmio via instância recursal}

A instância recursal, quando presente, não relativiza a soberania do júri, mas traz idoneidade ao processo de seleção e apuração, pois institui o contraditório: o direito a ter um contra-argumento em relação a sentenças. É importante enfatizar que, quando auditados, as auditorias não são instâncias recursais ou uma espécie de Corregedoria e de Ministério Público, no âmbito do prêmio, com poder de sanção e impugnação de sentenças. Até porque costumam ser empresas de auditoria privada contratadas pela premiação no sentido de agregar um status de lisura aos processos. As auditorias trabalham com um olhar sobre os procedimentos de apuração e geram relatórios para o premiador (organizações); mas não para premiados (vencedores, menções honrosas) ou premiáveis (candidatos, concorrentes).

\section{Estruturante 6 - Quem são os jornalistas premiados: profissionais ou estudantes?}

Quanto a jornalistas profissionais ou estudantes, recentemente, o número de prêmios com a categoria "estudantil" tem aumentado vertiginosamente (dando espaço inclusive para premiações exclusivas), emancipando essa figura como subsidiária (até então, estudantes eram tratados somente como categoria e não como prêmio específico). Na pesquisa, foram identificados índices de premiações voltadas para o profissional (74\%), estudante (5\%), ambos (14\%), sendo que alguns editais/ regulamentos não expressam $(7 \%)$.

44 ALCEU - n.33 - jul./dez. 2016 
As candidaturas são balizadas pela prescrição do registro profissional de jornalista (Delegacia Regional de Trabalho - DRT, do Ministério do Trabalho e Emprego -MTE). Quando se trata de categoria ou prêmio que verse sobre estudante universitário, há a condição de candidatura mediante anuência de um professor jornalista, que assine o trabalho. Os alunos e professores devem ser de Instituições de Ensino Superior (IES) com registro no Ministério da Educação (MEC). O desafio nessas categorias universitárias não é o de se publicar material em algum veículo profissional e comercial, mas no jornal laboratório (impresso ou web) com circulação no campus. Não foi detectado que os estudantes tivessem recompensas em dinheiro. No caso deles, foi identificado que recebem ferramentas de trabalho, como notebooks. Os professores também recebem o mesmo tipo de galardão.

O Instituto Ethos, organismo do Terceiro Setor, ajuda organizações interessadas a formular e estruturar prêmios, como no caso do Prêmio Itaú de Finanças Sustentáveis, que é um tipo de prêmio que sai da questão estrita do jornalismo econômico com noticiário sobre mercado e enfatiza as finanças pessoais, familiares e domésticas. Este prêmio tem uma questão interessante no tocante a estudantes: praticamente todas as premiações versam sobre a graduação, mas este foca também nos estudantes de pós-graduação. Da amostra final, somente o Prêmio Itaú de Finanças Sustentáveis abre o leque universitário para a pós. E apenas o Prêmio José Chalub Leite 1 tem uma categoria que premia matérias veiculadas em jornal-laboratório, que é algo diferente de se receber inscrições de trabalhos universitários veiculados (ou não).

\section{Estruturante 7 - Apoio de sindicatos e associações profissionais e patronais}

Quanto a tipo de sindicato/associação tentamos demonstrar o jornalista em associações ou sindicatos que prestam apoio às premiações, principalmente na questão de ter jornalistas na composição do júri para o julgamento par a par dos trabalhos. Entidades sindicais respondem por 30\%, patronais por 5\% (Prêmio AGERGS/ Banrisul e Prêmio Engenho de Comunicação) e há um grupo que contempla ambos 5\% (Prêmio FEAC e Prêmio Vladimir Herzog Anistia/DH). Mas, a maioria não proporciona avaliação em pares: jornalista por jornalista. Importante notar que os jornalistas acadêmicos, oriundos da ciência, só constam como expressos no Prêmio Vladimir Herzog Anistial $D H$. E que este prêmio entra como ambos porque tem 11 entidades associadas a ele.

É frequente a participação de sindicatos, principalmente os profissionais, fazendo parte das premiações. Sem falar em prêmios próprios dos sindicatos, não como apoiadores, mas como realizadores. É o caso do COJIRA: Prêmio Abdias Nascimento, de igualdade racial ${ }^{2}$. E a multiplicação de seus papéis também, como no caso acreano em que o Sindicato dos Jornalistas do ACRE tem o seu próprio prêmio (gestor e financiador), é parceiro de outras premiações (patrocinador, apoiador) e faz parte de júris de outros (sistema perito). 


\section{Estruturante 8 - Temas humanísticos mais utilizados nas pre- miações}

Os prêmios figuram como elementos de normatividade e prescrição de ethos, valores e procedimentos na cultura profissional jornalística (Schudson, 1993). As organizações que editam premiações podem ser entendidas como definidores primários não somente no processo de produção da notícia e nas rotinas produtivas (modo direto), mas também das chancelas de mérito jornalístico extra-organizacionais por meio dos prêmios na cultura profissional (modo indireto), influenciando o jornalista na questão do que é ou não notícia (news judgement) (Tuchman, 1993: 85). É nesse sentido que multiplicam-se a cada dia prêmios de ordem humanística (Dias, 2014d, 2013a, 2013b).

Primeiramente, tratamos de temas humanísticos agrupando-os em palavras guarda-chuva. Logo, a categoria Ambiental seria termo guarda-chuva para expressões como: "Informação Científica, Tecnológica e Ambiental" (1), "Meio Ambiente" (2), "Conscientização ambiental" (3), "Meio Ambiente" (4), "Sustentabilidade" (5), "Desenvolvimento sustentável" (6). O intuito foi o de mapear os temas por aproximação lexical e não conceitual, pois há grande diferença entre "ambientalismo", "sustentabilidade", "fauna e flora", "meio ambiente", "consciência ambiental" e "ecologia", expressões que apareceram nos regulamentos. A ideia principal era checar se os prêmios trabalham (ou não) dentro do eixo de 8 Objetivos do Milênio, políticas públicas agenciadas pela ONU, Unesco e Unicef. Encontramos o tema Eletricidade e Segurança de Energia (2\%), Educação (25\%), Código de Defesa do Consumidor (15\%), Combate ao Crime Organizado (5\%), Saúde (5\%), Idosos (2\%), Infância e Adolescência (15\%), Portadores de Necessidades Especiais (10\%), Igualdade Racial (2\%), Recursos Hídricos(2\%), Cidadania (10\%), 8 Objetivos do Milênio (2\%), Bem Estar Social (5\%).

A julgar pela promoção de metas e valores, que ora coincidem, ora não, com valores deontológicos do jornalismo brasileiro, a correspondência relativa a direitos civis é considerável, no tocante ao dever de defesa e promoção das garantias individuais e coletivas, em especial as das crianças, dos adolescentes, das mulheres, dos idosos, dos negros e das minorias ${ }^{3}$.

O prêmio da Câmara Brasileira de Comércio Eletrônico (camara-e-net) e do Movimento internet Segura (MIS) tem como base o Código de Defesa do Consumidor, sendo um dos poucos que não enfatiza a questão dos direitos humanos e temas similares, bem como do protocolo PNUD, além de parceiros como ONU, Unesco e Unicef. Em geral, não se percebem prêmios na amostra que versem sobre direito dos animais (1), direito dos idosos (2), direito dos portadores de necessidades especiais (3) etnias e igualdade racial (4) e temas não muito financiados pelo PNUD, que dão ênfase mais a gênero, infância e adolescência ${ }^{4}$. Dos prêmios, apenas dois do judiciário dão 
atenção aos idosos (Prêmio $A M B^{5}$ e Prêmio $C N P G^{6}$ ) e, apenas um à etnia e igualdade racial (Prêmio Abdias Nascimento). Ressalta-se ainda que, apesar dos 8 Objetivos do Milênio enfatizarem muito a questão do gênero, apenas um prêmio da amostra final versa sobre este tema (Troféu Mulher Imprensa).

O Prêmio OCEPAR, além de um dos Objetivos do Milênio (meio ambiente), trabalha com um tema coletivo chamado de bem-estar social, que aparece em três premiações da Confederação Nacional dos Bispos do Brasil (CNBB) com o nome de bem comum: Troféu Dom Helder, Troféu Clara de Assis, Troféu Margarida de Prata e Troféu Microfone de Prata. Esses prêmios da CNBB são também de índole bem coletiva: distribuição de renda, formação profissional do cidadão, sustentabilidade relacionada ao sucesso econômico, saúde coletiva e crédito entre cooperativas de trabalho.

Dentro do Prêmio Embratel há o Troféu Tim Lopes de jornalismo investigativo, que não se confunde com o Prêmio Tim Lopes de Jornalismo Investigativo (Rede Globo) e nem com o Concurso Tim Lopes de Jornalismo Investigativo (ANDI) ${ }^{7}$, ambos da mesma modalidade, mas com uma diferença sobre premiar pautas sobre reportagens (pré-produção) e reportagens já veiculadas (pós-produção). O que gera uma grande tensão: existe a crítica de que só se pode premiar Jornalismo Investigativo depois da reportagem veiculada (pós-produção). E que a premiação dessas pautas (pré-produção) não passa de mimetismo, pois seria "matéria paga" ou o "pagamento para se fazer matéria" . Entretanto, a Associação Brasileira de Jornalismo Investigativo (ABRAJI) e da Federação Nacional de Jornalistas (FENAJ) dão apoio a esta iniciativa.

O Prêmio Embratel tem ainda categorias de jornalismo esportivo, jornalismo cultural, jornalismo científico. Não fala em ambientalismo e nem consciência ambiental, mas em "responsabilidade socioambiental". Também não falam em educação, mas em "problemas sociais do Brasil" (moradia, alimentação, saúde, saneamento, meio ambiente). O curioso é a verbalização do Prêmio Embratel em relação à solução e à superação destes problemas brasileiros, como acontece com o Prêmio FEAC. O que pode ser entendido como uma forma difusa de tratar dos Objetivos do Milênio (OMD), ao se olhar para as metas de Erradicar a pobreza extrema e a fome (Objetivo 1), Atingir o ensino básico universal (Objetivo 2) e Estabelecer parceria mundial para o desenvolvimento econômico-social (Objetivo 8).

\section{Estruturante 9 - Temas globais mais utilizados: como as 8 Metas do Milênio}

Depois, quanto às metas do milênio, tentamos enquadrar todos os prêmios nos 8 OMD. Novamente, a problemática dos termos guarda-chuva ${ }^{9}$ e léxicos por aproximação ${ }^{10}$. Sabemos que o termo "saúde infanto-juvenil" é muito mais amplo do que "reduzir a mortalidade infantil", mas não buscamos a correspondência total e conceitual dos termos dos regulamentos ou em editais do PNUD. Não se trata de 
uma checagem dos temas do PNUD em si. O intuito foi o de vislumbrar tematicamente a correspondência dos prêmios com temas de cooperação internacional, pois são entidades com essas chancelas da ONU, Unesco e Unicef, umas das que mais têm penetração no meio jornalísticos e estratégias de premiações desenvolvidas, a julgar pelo Terceiro Setor.

Neste sentido, $38 \%$ dos prêmios poderiam ser entendidos como desenvolvedores do milênio, a partir da concepção dos organismos internacionais, sendo que $43 \%$ não. Algo perceptível: os prêmios que evocam os valores humanos praticamente recaírem sobre Objetivos do Milênio, como: ambiental, criança e adolescente e educação. O foco está em pessoas como: a criança, o adolescente, a mulher e temas orbitais a eles. Tematicamente, desenvolvimento nacional, desenvolvimento internacional e a saúde coletiva praticamente não aparecem.

\section{Estruturante 10 - Qual tipo de mídia é mais utilizada?}

O jornalismo é uma profissão premiada, como temos visto. Os prêmios operam em relação a diversos conceitos identificados em teorias da comunicação, tais como: controle do seu trabalho (Breed, 1993) nas rotinas produtivas (Tuchman, 1993), a questão da ação pessoal e seleção de notícias por um filtro (White, 1993), o profissionalismo (Soloski, 1993), sofrimento com a pressão do tempo (Schlesinger, 1993), relacionamento entre fontes e os jornalistas (Molotch e Lester, 1993), poder das fontes como definidores primários (Hall et al., 1993), além de questões relativas à visão de mundo e cultura profissional (Schudson, 1993).

Mas, o curioso é que nem todas as funções, que fazem parte da divisão do trabalho nas redações, são premiáveis. O repórter continua sendo a figura central. E como orbitais, citam-se: colunista, apresentador, âncora, produtor, pauteiro, locutor, dentre outros. $\mathrm{Na}$ amostra, encontramos algumas menções dessas funções, mas bem específicas. E quanto ao tipo de mídia que os prêmios gostariam de acessar temos, em termos numéricos: jornalismo impresso (34 ocorrências), radiojornalismo (30), telejornalismo (30), fotojornalismo (19) e webjornalismo (26). A mesma informação numérica, representada de forma distributiva em partes, traz a relação: $24 \%$ (impresso), 22\% (rádio), 22\% (TV), 14\% (foto) e 18\% (web). Sendo assim, para os prêmios, a figura central do repórter está no impresso, seguido de um empate entre rádio e TV. E o ambiente web já supera a fotografia em jornalismo como objeto de premiação.

\section{Estruturante II - Quais os modelos jornalísticos mais utilizados?}

As organizações tendem a influenciar diretamente o processo de produção da notícia (Molotch e Lester) e as rotinas produtivas, mas também influenciam 
indiretamente por meio de uma cultura meritocrática premiativa ao apontar para a subjetividade do indivíduo (cosmovisão do jornalista) na cultura profissional jornalística. Nesse sentido, se torna importante o modelo jornalístico utilizado como protocolo de avaliação e certificação da performance e mérito. Na amostra, os modelos e modalidades mais tratados em regulamentos são: jornalismo informativo (35 ocorrências), jornalismo organizacional (8), jornalismo econômico (5), jornalismo científico (6) e jornalismo público (27).

O enquadramento dessas modalidades se dá também por termos guarda-chuva, na pesquisa, pois nenhum regulamento nomina da mesma forma expressa o tema de dada edição ou modelos jornalísticos. Um bom exemplo é aplicado à modalidade de jornalismo público que aparece como "jornalismo cidadão", por vezes. É um termo pouco utilizado. Aparecem as ocorrências das expressões: "direitos do consumidor", "cidadania", "direitos do cidadão", "direitos humanos", "direitos civis", dentre outras expressões que apontam para um objetivo comum a tal modelo.

\section{Estruturante 12 - A questão do direito autoral e patrimonial dos trabalhos}

$\mathrm{Na}$ amostra, alguns regulamentos tinham de modo expresso consideração sobre direito autoral e patrimonial para incorporação de matérias inscritas; e até o uso posterior delas em material de divulgação ou para fins educativos (54\%). O restante não se expressa sobre tal $(46 \%)^{11}$.

No direito autoral, os prêmios costumam trazer para si o direito de reprodução e exibição. E ainda assinalam que a reprodução do material, após o término da edição da premiação, poderá ser feita em qualquer parte do território nacional ou no exterior. Eles recolhem essa autorização tacitamente no ato de inscrição, quando o jornalista (ou equipe) assina o formulário de candidatura. Não costumam utilizar a palavra plágio, mas pedem a "boa origem" e "originalidade" dos trabalhos. E se preocupam muito nos regulamentos com a veiculação de conteúdo não-jornalístico, quer seja cinema (documentário) se fazendo passar por reportagem (exemplo: Prêmio $A M B^{12}$ ), quer seja material oriundo de blogs não-jornalísticos (também o Prêmio $A M B$ ).

Os trabalhos são apropriados aos direitos autorais e patrimoniais com o objetivo de aglutinação daquele conteúdo em livros, folhetos, relatórios, campanhas e publicações organizacionais. Não são apenas com viés de agenda no noticiário, mas de compilação de conhecimento para material didático e informativo.

Nessas inserções sobre direito autoral e patrimonial é comum os prêmios se resguardarem de possíveis litígios quanto ao uso das peças inscritas. As premiações utilizam os formulários de inscrição e as assinaturas dos candidatos também como documento que prova a anuência formal dos candidatos com a divulgação dos 
trabalhos pós-premiação em cursos, folderes, material profissional, dentre outros.

Nessa mensura computamos como expressos, inclusive, se apenas uma espécie de direito fosse mencionada. Não houve a distinção entre quem fala em direito autoral e quem fala em direito patronal, até porque cai, novamente, na questão de captação, classificação e tabulação dos dados a partir de palavras-chave na amostra que se expressam de maneira diferente sobre um mesmo termo.

\section{Estruturante 13 - A apropriação de material para fins didáticos}

O indicativo desenvolve o fato de que alguns premiadores se apropriam dos trabalhos inscritos e os utilizam posteriormente em atividades com fins educativos (19\%), sendo o restante omisso quanto a esta informação (81\%). Há regulamentos que trazem considerações sobre o objetivo do prêmio de aumentar o noticiário sobre dado tema, mas também de produzir conhecimento ${ }^{13}$. O uso de termos com acepção de formação profissional concluída ou de comprovante de conclusão de um curso (diploma, certificado), além dos que evocam certa concorrência em prol de um ranking (troféu, medalha, insígnia) nos prêmios conota uma questão de educação e de ranking do melhor procedimento. As seções que associam profissão a educação foram construídas nesse sentido. Este indicativo tentava vislumbrar o uso de material jornalístico submetido a dado processo de premiação como material de estudo ou formação, formalizado em cursos, ou até mesmo a publicação de material educativo. O Prêmio Abramge de Medicina e de Jornalismo ${ }^{14}$ tem um rico detalhamento do histórico de vencedores em seu site, com registros dos últimos 15 anos. É das premiações mais organizadas. Ressalta-se que os prêmios trabalham com edições temáticas e dossiês, para ter uma unidade comum de candidaturas e trabalhos a serem avaliados.

Esclarecemos que "não devolver os trabalhos inscritos" (medida administrativa) é diferente de "usar os trabalhos para fins educacionais ou divulgação depois" (direitos autorais), esta última, ação do Prêmio CBN Jornalismo Universitário.

\section{Estruturante I 4 - Quais têm responsabilidade legal relativa ao plágio}

A cultura profissional é um complexo emaranhado de retóricas de fachada e astúcias táticas, de códigos, estereótipos, símbolos, tipificações latentes, representações de papéis, rituais e convenções, relativos às funções dos mass media e dos jornalistas na sociedade, à convenção do produto-notícia e às modalidades que superintendem à sua confecção (Wolf, 2001: 189). Sendo que o profissionalismo controla o comportamento dos jornalistas de dois modos relacionados: estabelecendo padrões de conduta e normas de comportamentos (1); e determinando o sistema de recompensa profissional (2) (Soloski, 1993: 95). 
No Código de Ética dos Jornalistas Brasileiros existe preceito de que o jornalista não é responsável por obras adulteradas por terceiros, que é uma dimensão ética relativa à adulteração. $\mathrm{O}$ intuito dessa mensura foi investigar se isso se configuraria em alguma questão legal, relativa ao Código Penal, nos editais/regulamentos das premiações. Pensávamos na questão dos regulamentos coibirem, formalmente, a inscrição de matérias que pudessem ser suspeitas quanto à idoneidade e responsabilidade profissional do jornalista, no tocante a crimes de honra e de direito autoral (ocorrência de 65\% deste tipo de precaução), sendo que o restante é omisso sobre o tema (35\%).

\section{Conclusão}

Esse foi um breve panorama de algumas estruturantes dos prêmios em jornalismo, no Brasil. A pesquisa-tese que serviu de base para este artigo foi realizada numa linha de pesquisa que tem como mote a teoria da notícia. E este doutoramento é resultado de achados de uma pesquisa-dissertação realizada no mesmo PPG. O estudo dos prêmios tem rendido bastante para o autor e sido objeto de várias publicações acessórias, a este artigo, sobre o tema: Dias (2013, 2008, 2014e, 2014d, 2014c, 2014b, 2014a, 2013b, 2013a, 2012c).

Como o artigo descreve 14 condições estruturantes, expôs esse universo de forma mais descritiva, utilizando-se da citação de alguns aspectos teórico-metodológicos, além de discussões e resultados acessórios, já trabalhados em outros artigos. No intuito de continuar as investigações sobre o tema, o pesquisador cadastrou um grupo de pesquisa nos diretórios do CNPq (sigilo - blind review) e um projeto de pesquisa com financiamento do CNPq sobre o tema (sigilo - blind review).

Professor da Universidade Católica de Brasília (UCB)

Recebido em maio de 2016.

Aceito em agosto de 2016.

\section{Notas}

1. Sindicato dos Jornalistas Profissionais do Estado do Acre (Sinjac).

2. Na amostra, entra o regulamento do Cojira/RJ, Comissão de Jornalistas pela Igualdade Racial do Sindicato dos Jornalistas Profissionais do Município do Rio de Janeiro (Cojira/RJ), mas os outros dois podem ter prêmios editados no mesmo sentido, a julgar pelo Núcleo de Comunicadores Afro-brasileiros do Rio Grande do Sul do Sindicato dos Jornalistas Profissionais no Estado do Rio Grande do Sul (1), Comissão de Jornalistas pela Igualdade Racial do Sindicato dos Jornalistas Profissionais do Estado de São Paulo (Cojira/SP) (2).

3. FENAJ, Código de Ética dos Jornalistas Brasileiros, Art. 6º 2007. 
4. Ressalta-se que muitos prêmios são apenas para aumentar o poder das pautas no noticiário (visibilidade institucional). E que nem todos os prêmios com apoio dessas instituições sejam politizados como os de direitos humanos (Políticas Públicas), que costumam ter ONU, Unicef, Unesco por trás. Alguns têm o enfoque mais de assistência social da mulher, criança, adolescente, idosos, etc.

5. Associação dos Magistrados Brasileiros (AMB), entidade que reúne 14 mil juízes em todo o Brasil.

6. Conselho Nacional dos Procuradores-Gerais (CNPG).

7. Concurso Tim Lopes de Jornalismo Investigativo (ANDI) tem apoio de Childhood Brasil, Fundo das Nações Unidas para a Infância (Unicef), Organização Internacional do Trabalho (OIT), da Associação Brasileira de Jornalismo Investigativo (Abraji) e da Federação Nacional de Jornalistas (Fenaj). Detalhe: ABRAJI e FENAJ no mesmo prêmio.

8. Prof. Dr. Solano Nascimento no seminário de pesquisa II, da Linha de Jornalismo e Sociedade do PPGFAC/UnB.

9. Desenvolvimento nacional (Objetivo 1), Educação (Objetivo 2), Gênero (Objetivo 3), Saúde Infanto-Juvenil (Objetivo 4), Saúde materna (Objetivo 5), Saúde coletiva (Objetivo 6), Sustentabilidade (Objetivo 7) e Desenvolvimento internacional (Objetivo 8).

10. Erradicar a pobreza extrema e a fome (Objetivo 1), Atingir o ensino básico universal (Objetivo 2), Promover a igualdade entre sexos e a autonomia das mulheres (Objetivo 3), Reduzir a mortalidade infantil (Objetivo 4), Melhorar a saúde materna (Objetivo 5), Combater o HIV/AIDS, a malária e outras doenças (Objetivo 6), Garantir a sustentabilidade ambiental (Objetivo 7) e Estabelecer parceria mundial para o desenvolvimento econômico-social (Objetivo 8).

11. Nessas inserções sobre direito autoral e patrimonial é comum os prêmios se resguardarem de possíveis litígios quanto ao uso das peças inscritas. As premiações utilizam os formulários de inscrição e as assinaturas dos candidatos também como documento que prova a anuência formal dos candidatos com a divulgação dos trabalhos pós-premiação em cursos, folders, material profissional, dentre outros.

12. Associação dos Magistrados Brasileiros (AMB), entidade que reúne 14 mil juízes em todo o Brasil.

13. Um caso interessante é o da ANDI, que tem uma editora própria, e faz uso de muito desse material. Apesar dessa ressalva sobre apropriação dos trabalhos inscritos, no processo de apuração é perceptível que pouquíssimos prêmios disponibilizam as matérias vencedoras em dada categoria para consulta na internet. É corrente o protocolo de lançamento de edital e a divulgação de resultados. Entretanto, a divulgação dos trabalhos vencedores ou de menção honrosa não é muito comum. 14. Associação Brasileira de Medicina de Grupo (Abramge).

\section{Referências}

BREED, W. Controle social na redação. Uma análise funcional. p. 152-156. In: TRAQUINA, N. (Org.) Jornalismo: questões, teorias e "estórias”. Lisboa: Vega, 1993.

52 ALCEU - n.33 - jul./dez. 2016 
BORGES, Iara. A presença da mídia das Fontes Agência Senado em Notícia da Folha Online e O Globo Online. Dissertação de Mestrado em Comunicação, UnB 01/12/2008.

CASSOL, Ivone. Prêmio Esso e as transformações da reportagem. Dissertação de Mestrado em Comunicação, PUCRS, 1997.

CASTILHO, Marcio. "Patrimônio dos Próprios Jornalistas": o Prêmio Esso, a identidade profissional e as relações entre imprensa e Estado (1964-1978). Tese de Doutorado em Comunicação, UFF, 2010. CONCURSO TIM LOPES. Regulamento 2010. Brasília, 2010.

DIAS, Robson. Prêmios em Jornalismo: Paradigmas em transição. Tese de Doutorado em Comunicação, UnB, 2013.

A influência do prêmio Jornalista Amigo da Criança sobre o profissional de jornalismo:

estudo de caso. Dissertação de Mestrado em Comunicação, UnB, 2008.

. Estado da arte da pesquisa acadêmica sobre prêmios em jornalismo. E-Compós (Brasília), 2014e, v. 17, p. 01-16.

Meritocracia do sujeito: prêmios em jornalismo pautados pela cidadania como flexibilização da objetividade jornalística. Revista Eletrônica do Programa de Pós-Graduação em Mídia e Cotidiano, v. 3, p. 414-431, 2014d.

. Honra ao mérito: como a instituição do Prêmio Esso contribuiu para a adoção dos referenciais de objetividade jornalística no Brasil. Comunicação \& Inovação (Online), v. 15, p. 126-137-126, 2014c.

Prêmios em jornalismo: a cultura meritocrática premiativa dentro da cultura profissional jornalística. Eptic (UFS), v. 16, p. 54-68, 2014 b.

. Meritocracia na midiocracia: reflexões sobre prêmios em jornalismo na cultura profissional jornalística. Revista FAMECOS (Online), v. 21, p. 525-621, 2014a.

. Prêmios em jornalismo: a emergência de um novo ethos profissional. Comunicação E Inovação (Online), v. 14, p. 1-50-56, 2013 b.

. O jornalismo e a cidadania como agentes de mudança em relação aos critérios de objetividade. Comum (FACHA), v. 15, p. 60-75, 2013 a.

. Adesão ao trabalho jornalístico: uma reflexão sobre labor em diálogo com perspectivas da sociologia das profissões. Logos (UERJ. Impresso), v. 19, p. 136-151, 2012c. FERREIRA, Soraya. Sem final feliz: Síndrome de Peter Parker e as fotos do Rio de Janeiro nos Prêmios Esso de Jornalismo e Imprensa Embratel/Claro. Revista Estudos de Jornalismo, v. 1, p. 62-78, 2014.

e FACCIN, Milton Júlio. Jornalismo de roupa nova: considerações sobre e a identidade e a prática profissional a partir do Prêmio Imprensa Embratel. Brazilian Journalism Research (Online), v. 9, p. 172-190, 2013.

GONÇALVES, Rogério. O superhomem pendura o paletó na repartição: a gênese do jornalista legislativo. Dissertação de Mestrado em Comunicação, UnB, 2010.

HACKETT, Robert. Declínio de um paradigma? A parcialidade e a objetividade nos media noticiosos. In: TRAQUINA, Nelson (Org.) Jornalismo: questões, teorias e "estórias". Lisboa: Vega, 1993. p. 101-132.

HALL, Stuart, CHRITCHER, Chas, JEFFERSON, Tony et alii. A produção social das notícias: o "mugging" nos media. In: TRAQUINA, Nelson (Org.) Jornalismo: questões, teorias e "estórias". Lisboa: Vega, 1993.

MAGNO, Ana. A agonia da reportagem: das grandes aventuras da imprensa brasileira à crise do mais

ALCEU - n.33 jul./dez. 201653 
fascinante dos gêneros jornalísticos: uma análise das matérias vencedoras do Prêmio Esso de Jornalismo. Dissertação de Mestrado em Comunicação, UnB, 2006.

MOLOTCH, Harvey e LESTER Marilyn. As notícias como procedimento intencional: acerca do uso estratégico dos acontecimentos de rotina, acidentes e escândalos. In: TRAQUINA, Nelson (Org.) Jornalismo: questões, teorias, "estórias". Lisboa:Veja, 1993. p. 34-53.

PASSOS, Lucio. A produção de efeitos de sentido nas fotografias da imprensa brasileira: análises técnicas, plásticas e semânticas. Dissertação de Mestrado em Comunicação, Universidade do Tuiuti, 2007. PRÊMIO ABDIAS NASCIMENTO. Regulamento 2010. Rio de Janeiro, 2010.

PRÊMIO ABERJE. Regulamento 2010. São Paulo, 2010.

PRÊMIO ABRAMGE DE MEDICINA E DE JORNALISMO. Regulamento 2011. São Paulo, 2011.

PRÊMIO AMB DE JORNALISMO. Regulamento 2010. Brasília, 2010.

PREMMIO AGERGS/ BANRISUL. Regulamento 2011. Rio Grande do Sul, 2011.

PRÊMIO AUTOMAÇÃO DE JORNALISMO. Regulamento 2011. São Paulo, 2011.

PRÊMIO CBN JORNALISMO UNIVERSITÁRIO. Regulamento 2011. Rio de Janeiro, 2011. PRÊMIO COMUNIQUE-SE. Regulamento 2011. Rio de Janeiro, 2011.

PRÊMIO CNPG. Regulamento 2010. Brasília, 2010.

PRÊMIO ENGENHO DE COMUNICAÇÃO. Regulamento 2011. Brasília, 2011.

PRÊMIO JOSÉ CHALUB LEITE. Regulamento 2010. Acre, 2010.

PRÊMIO ITAÚ DE FINANÇAS SUSTENTÁVEIS. Regulamento 2011. São Paulo, 2011.

PRÊMIO SEBRAE. Regulamento 2010. Brasília, 2010.

PRÊMIO VLADIMIR HERZOG. Regulamento 2010. Rio de Janeiro, 2010.

TROFÉU DOM HELDER. Regulamento 2011. Brasília, 2011.

TROFÉU CLARA DE ASSIS. Regulamento 2011. Brasília, 2011.

TROFÉU MARGARIDA DE PRATA. Regulamento 2011. Brasília, 2011.

TROFÉU MICROFONE DE PRATA. Regulamento 2011. Brasília, 2011.

PRÊMIO ESSO DE JORNALISMO. Regulamento 2010. São Paulo, 2010.

PRÊMIO FEAC DE JORNALISMO. Regulamento 2011. Campinas, 2010.

PRÊMIO OCEPAR. Regulamento 2010. São Paulo, 2010.

SANT'ANNA, Francisco. Mídia das fontes: um novo ator no cenário jornalístico brasileiro. Um olhar sobre a ação midiática do Senado Federal. Brasília: Edições Técnicas do Senado Federal, 2009. v. 1000. 582 p.

SANTOS, Sandra. Um estudo das fotos vencedoras do prêmio Vladimir Herzog de anistia e direitos humanos. Dissertação de Mestrado em Comunicação, USP, 2004.

SCHLESINGER, Philip. Os jornalistas e a sua máquina do tempo. In: TRAQUINA, Nelson. (Org.). Jornalismo: questões, teorias e "estórias". Lisboa: Vega, 1993.

SCHUDSON, Michael. A política da forma narrativa: a emergência das convenções noticiosas na imprensa e na televisão. In: TRAQUINA, Nelson (Org.). Jornalismo: questões, teorias e "estórias". Lisboa: Vega, 1993.

SENRA, Stella. O último jornalista: imagens de cinema. São Paulo: Estação Liberdade, 1997.

SOLOSKI, John. O jornalismo e o profissionalismo: alguns constrangimentos no trabalho jornalístico. In: TRAQUINA, Nelson. Jornalismo: questões, teorias e "estórias". Lisboa: Vega, 1993. SOUSA, Jorge Pedro. Elementos de teoria e pesquisa da comunicação e da mídia. Florianópolis: Letras Contemporâneas, 2003.

54 ALCEU - n.33 - jul./dez. 2016 
TRAQUINA, Nelson (Org.). Jornalismo: questões, teorias, “estórias”. Lisboa: Vega, 1999.

.(Org.). O estudo do jornalismo no século XX. São Leopoldo: Ed. Unisinos, 2001.

TUCHMAN, Gaye. A objetividade como ritual estratégico: uma análise das noções de objetividade dos jornalistas. In: TRAQUINA, Nelson. Jornalismo: questões, teorias e "estórias". Lisboa: Vega, 1993. p. 74-90.

WHITE, D. M. O gatekeeper: uma análise de caso na seleção de notícias. In: TRAQUINA, N. (Org.). Jornalismo: questões, teorias e "estórias". Lisboa: Veja, 1993.

\section{Resumo}

Os prêmios em jornalismo são dispositivos utilizados pelos news promoters (Molotch e Lester) e definidores primários (Hall et all.) no intuito de acessar a cultura profissional (Schudson) e promover a certificação extra-organizacional de um ethos exemplar do que seria o bom e o mau, o êxito e o fracasso na profissão, nos moldes do profissionalismo (Soloski). A partir do estudo de 114 premiações no Brasil, o artigo divulga resultados de uma tese de doutorado que mapeia 14 condições sobre as quais os prêmios se organizam.

\section{Palavras-chave}

Jornalista. Meritocracia. Prêmios. Newsmaking.

\section{Abstract}

Fees journalistic merit: Prizes in Journalism and then structuring

Prizes in Journalism are devices used by news promoters (Molotch and Lester) and primary definers (Hall et all.) in order to access the professional culture (Schudson) and promote certification extra-organizational ethos of a copy of which would be the good and bad, success and failure in the profession, along the lines of professionalism (Soloski). From the study of 114 awards in Brazil, the paper discusses the results of a doctoral thesis that maps 14 conditions upon which the awards are organized.

\section{Keywords}

Journalist. Meritocracy. Awards. Newsmaking.

\section{Résumé}

Honoraires mérite journalistique: Prix en journalisme et ensuite une structuration

Les prix en journalisme sont des dispositifs utilisés par les promoteurs de nouvelles (Molotch et Lester) et définisseurs primaires (Hall et tous) afin d'accéder à la culture professionnelle (Schudson) et promouvoir la certification éthique extra-organisationnelle d'une copie de ce qui serait la bonne et le mauvais, le succès et l'échec dans la profession, le long des lignes de professionnalisme (Soloski). De l'étude de 114 prix au Brésil, le document examine les résultats d'une thèse de doctorat Ce qui mappe 14 conditions sur les prix sont organisés.

\section{Mots-clés}

Journaliste. Méritocratie. Prix. Newsmaking 